\title{
TERRITORIO, PAISAJE Y MARKETING GLOBAL. IMAGINARIOS EN LA CONSTRUCCIÓN DE LA PATAGONIA COMO MARCA
}

\author{
JUAN CARLOS RODRÍGUEZ T.", \\ PATRICIO MEDINA H."' \& SONIA E. REYES H."
}

\section{RESUMEN}

Se parte del supuesto de que el espacio y el territorio patagónico binacional poseen una definida identidad y un gran capital simbólico que excede lo puramente geográfico y que trasciende a Chile y Argentina, lo que se materializa en la construcción de la Patagonia como producto. Sostenemos que el componente geográfico y espacial ha quedado incluido en un marketing global, valorizándose sus atributos como una marca. En esta marca hay un doble juego: una oferta encadenada al espacio y al territorio mediada por un imaginario que porta la marca asociado a una "condición" social y una demanda asociada a una posición social representada por turistas-consumidores que buscan experiencias "únicas" y pobladores foráneos que quieren ser pioneros, es decir, los primeros y tal vez los últimos en vivir el espacio libre.

Por tanto, el artículo busca identificar algunas dimensiones que contribuyen o dan forma a la construcción social de la Marca Patagonia. Desde la perspectiva de la oferta se distingue a los actores, qué ofrecen, a quiénes se les ofrece, cómo se promueve y se vende. El producto responde a la búsqueda de una "condición social distintiva" y re-crea un imaginario para ello. Desde la perspectiva de los consumidores: el producto-marca corresponde a una condición social que la consume.

Metodológicamente, existe un registro de información secundaria que contempla documentos visuales, de audio, periódicos, informes técnicos y académicos; y una estrategia etnográfica multicentrada y multisituada, que privilegia información proveniente de distintos lugares y tipos de informantes ${ }^{1}$.

PALABRAS CLAVE: Patagonia, naturaleza, capital, marca, imaginarios.

* Dr. en Antropología, Profesor Titular Facultad de Arquitectura de la Universidad de Valparaíso, Chile. juancarlosrodriguezt@ yahoo.com.

* Antropólogo, Profesor Escuela de Psicología de la Pontificia Universidad Católica de Valparaíso, Chile. pmedinahernandez@ yahoo.es.

Dra. en Sociología, Profesora Adjunta del Instituto de Sociología, Universidad de Valparaíso, Chile. sonia.reyes@uv.cl.

1 Este trabajo es parte del proyecto Fondecyt 1120795 Etnografía de la colonización y recolonización de Chiloé Continental. Actores, intercambios y conflictos. 


\title{
TERRITORY, LANDSCAPE AND GLOBAL MARKETING. IMAGES IN THE CONSTRUCTION OF PATAGONIA AS A BRAND
}

\begin{abstract}
This article starts from the premise that patagonic binational territory and space possess a defined identity, altogether with a considerable symbolic capital that exceeds the purely geographic dimension transcending the national identities of Chile and Argentina. This materializes the construction of Patagonia as a product. We sustain that the geographical and spatial components have been included in a global marketing strategy, rendering its attributes as a brand. This brand contains a twofold logic: a spatial and territorial offer mediated by an imaginary that sustains this brand associated to a social "condition". And also a demand associated to a social stratification represented by tourists and consumers who seek unique experiences; together with foreign residents who want to be pioneers, that is to say, the first and maybe the last ones of living in the open free space.

Therefore the article seeks to identify some of the dimensions that contribute and shape the social construction of the Patagonia brand. From an offer perspective it is possible to differentiate actors, what do they offer, to whom are they offering it to, and how it is promoted and sold. The product responds to the searching of a "distinctive social condition" that needs the reproduction of an imaginary according to this. From the consumer perspective the brand-product is consumed by a particular social condition.

The methodology applied in this study covers the revision of secondary sources ranging from audio and visual documentation, through journals to technical reports, together with a multicentered ethnographic strategy which privileges primary data provided by different categories of informers interviewed in different locations.
\end{abstract}

KEY WORDS: Patagonia, nature, capital, brand, imaginary.

\section{INTRODUCCIÓN}

Y de Chile podría decirse: Son siete países que, periódicamente, convergen a la capital, acrecientan su población y riqueza, pero viven aislados y en constante pugna. (Latorre 1965)

En este artículo buscamos realizar un análisis crítico y documentar de manera etnográfica la idea de una Patagonia producto, asociada a una "oferta verde" y una "demanda verde" que ayudan a reconfigurar el mapa económico, político, cultural y social reciente de la Patagonia de Chile, a través de acciones e imaginarios de distintos actores que establecen encuentros y desencuentros materiales y simbólicos. Para ello, hemos visualizado las influencias históricas y culturales presentes en el discurso sobre la Patagonia y observado el espacio descrito como una formación discursiva marcada por reglas políticas, económicas y culturales intencionadas que la visionan. De este modo, la Patagonia representa simultáneamente un lugar físico de diversas geografías y un cruce de emociones, acciones, apreciaciones y principalmente, imaginarios que le dan su forma actual. Comprendiendo a los imaginarios como los procesos subjetivos y de elaboración simbólica, ligados a la experiencia física y cultural de la espacialidad, sustentados en imágenes, imaginaciones y modos de representación que combinan información, creencias, vivencias y fantasías, con propósitos y efectos sobre la realidad, en la medida que ayudan creativa y persuasivamente a construir o definir lo real (Lindón et al. 2006).

En esta perspectiva seguimos la línea de Edward Soja (1996) a partir de su trilogía sobre la construcción del espacio: de la espacialidad (spaciality), socialidad (sociality) e historicidad (historicallity), como formas de ser y estar en el mundo. Con estas entradas, tratamos de reconocer la existencia de diferentes espacios: el percibido (material, en el que se pueden cartografiar y fijar las cosas empíricamente); el concebido (mental, subjetivo, de representaciones y de mapas mentales); y el vivido (participación, experiencia). Nos situamos en este tercer espacio, como superación del primero y el segundo, ya que nos permite abordar el territorio de la Patagonia 
desde una doble relación: a la imagen del tiempo y el espacio, así como al de los territorios vividos biográficamente, cuya modelación está dominada por la producción social de la política, la economía y la cultura.

Dentro de un programa de investigación territorial que tiene como centro la provincia de Palena, metodológicamente se priorizaron dos ejes para observar la construcción de lo que llamaremos la marca y de los imaginarios que la forman: 1) el registro de información secundaria, que contempla documentos visuales, de audio, periódicos, informes técnicos y académicos; 2) una estrategia metodológica multicentrada y multisituada (Marcus 1995), es decir, un procedimiento etnográfico que está más allá del single sited, con varios centros físicos y dispersos de observación, atención, registro y participación. Para estos efectos hemos seguido a Rodman (1992) y Marcus (1995), quienes proponen el análisis descentrado, teniendo varios lugares de registro y referencia (cercanos y lejanos), los que para efectos de este trabajo son locales, provinciales, regionales, nacionales e internacionales. Esta estrategia postula una etnografía de carácter móvil, que permite documentar la circulación de personas, objetos y discursos, siguiendo también su movimiento (Marcus 1995), porque entendemos que lo real, lo es de muchas maneras. Sumada la experiencia etnográfica a fuentes secundarias, buscamos también documentar las posibilidades de vida imaginadas (Appadurai 2001:69-70) por las poblaciones y los actores que entran al campo patagónico, entendiendo que participan autoridades del gobierno central, regional $y$ local, población residente, alóctonos, turistas, académicos, ambientalistas y empresarios locales y de corporaciones transnacionales, los que visionan con distintos intereses y fuerzas las posibilidades de esta macro región binacional.

\section{LA PATAGONIA DENTRO Y FUERA DE LOS LIMITES DEL ESTADO}

Políticamente, la Patagonia es el espacio y el territorio binacional del Cono Sur, compartido por Chile y Argentina, de aproximadamente un millón de kilómetros cuadrados, en el que existe una gran biodiversidad, grandes fuentes de recursos aún no explorados y otros no explotados del todo. En Argentina se trata de una Patagonia ocupada, aunque lejana de la Capital Federal; ésta incorpora al análisis el componente indígena mapuche y tehuelche, la industrialización, el ferrocarril; aunque algunas zonas son consideradas ambientalmente estériles. En Chile también es distante del centro político y administrativo, caracterizándose por la escasa y tardía presencia del Estado y de su agenciamiento, con una industrialización ganadera, principalmente en Magallanes, acompañada del desarrollo de la industria de los hidrocarburos, en la segunda mitad del siglo pasado. Corresponde a grandes extensiones de territorio que tanto en Pigafetta como en Darwin adquieren la fisonomía histórica de un despoblado y que para Ernesto Bohoslavsky (2009) mantiene en la actualidad importante independencia respecto del poder central por las importantes compras de tierras y estancias por parte de extranjeros.

Las poblaciones patagónicas han transitado e intercambiado desde antes de la formación de los estados, configurando un habitus transfronterizo. Hasta el día de hoy las redes alimentarias, de educación, salud, trabajo y familia se han dispuesto binacionalmente $y$ configurado en un ir $y$ venir como itinerarios vitales y genealogías densas, permaneciendo como el sello de un "nosotros" por sobre la fijación de los límites administrativos y ciertos chauvinismos vividos en otras regiones y provincias de ambos países. Las fronteras no han operado como impedimento para el tránsito, sino que son sobrepasadas, espacializan la historicidad, y permanentemente aquí éstas han sido espacios sociales de gran dinamismo y alta complejidad (Bandieri 2011: 15), lo que ha permitido que al margen de los Estados las comunidades sean más colaborativas que antagónicas; las mismas posibilidades abiertas en la industria del petróleo, gas y las metalmecánicas en Argentina, junto con leyes de protección al trabajo, se han configurado como un gran mecanismo de atracción laboral para chilenos.

La Patagonia chilena se extiende, según algunos, desde Puerto Montt al sur, según otros comienza en Valdivia o Pucón, en la región de la Araucanía. Esta vasta extensión geográfica está compuesta en gran parte por accidentados archipiélagos que imposibilitan las conexiones 
terrestres entre las ciudades y regiones que allí se ubican, generando centros y periferias. De esta manera, las capitales regionales Coyhaique y Punta Arenas, no tienen conexión entre sí, ni por vía terrestre, ni marítima, ni aérea; lo que conlleva una incomunicación de las regiones y sus habitantes, sin embargo éstos luchan en la construcción de sus identidades de manera paralela y muchas veces autónoma del Estado, sintiéndose parte de la Patagonia. Esto ocurre, tal como lo analizaremos más adelante, debido a que sus problemáticas son comunes y por ende sus destinos. Desde ya, son variadas las diferencias históricas de estas regiones y sus capitales: Punta Arenas, la más austral, fue fundada tempranamente en 1848, contrastando con Coyhaique que se funda en 1929 y es capital regional recién en 1974 .

La menor presencia del Estado chileno en estos territorios, o de un pobre agenciamiento para no referirse a un Estado monolítico y unificador, indica la existencia de fronteras interiores naturales y culturales, ya que se trata de una geografía y topografía de difícil accesibilidad, con importantes problemas de distancia y conectividad, desde Puerto Montt al sur. Esto habla de una compleja colonización en grandes extensiones, muchas veces lejos del colono próspero, demostrando que con la existencia de comunidades en gran aislamiento el imaginario país toma una forma específicamente local. No hay una constitución de la identidad del tipo top down o de comunidad imaginada en los términos de Benedict Anderson (1993), sino una up down, ya que en muchos ámbitos es la actividad local la que define los limites de pertenencia y las propias fronteras de adscripción y reconocimiento de sus habitantes, fijando una representación particular de sí misma que configura su propia comunidad imaginada. Pequeñas comunidades que no alcanzan la categoría de ciudades adquieren mayormente la forma social y cultural up down, ya que se legitiman con recursos y capacidades propias, con actividades económicas ligadas a la pesca, la ganadería, la extracción de leña, trasportes, pequeño comercio $y$ actividades administrativas y públicas de bajo impacto y autonomía, con el objetivo de hacer más habitable y vivible la localidad (Municipio, Gobernación y colegios).

En el lado chileno, actualmente existen pocos caminos que faciliten la conectividad, muchos de ellos son ripiados y de difícil trazado, por lo que los inviernos largos y hostiles en la macrozona austral impiden el expedito desplazamiento, por lo que la proximidad a las despejadas pampas de la Patagonia argentina y la distancia y abandono, en muchos casos de las autoridades centrales de Chile, terminan por definir una identidad nacional precaria en el discurso y en la cultura cotidiana. En cambio, en lo local, el colectivo configura singulares experiencias culturales, psicológicas y de interacción en la vida social, que generan adhesión a ciertos modos de "construcción social de la realidad" (Berger \& Luckmann 1999), vividos como "identidad legitimadora", es decir, como autoconciencia de los particularismos geográficos, condicionada por el territorio, las referencias comunes y las continuidades de las prácticas en el tiempo (Molina 2011: 61-62), por lo que esta forma de residir al margen de los problemas país termina por autonomizarse de la idea de la nación.

Esto fortalece la idea de región o ecoregión patagónica, extensiva a Argentina en los vínculos de Punta Arenas con Río Gallegos o Ushuaia, Coyhaique con Comodoro Rivadavia y Futaleufú y Alto Palena con Trevelin y Esquel, como cualidad de una experiencia cultural autónoma y transfronteriza, anterior a la fijación de límites, que por ejemplo en la zona más austral se impone como preeminencia de lo magallánico o regional por sobre lo chileno (Molina 2011).

Un estudio del Ministerio de Obras Públicas indica que es la variable accesibilidad la que favorece o restringe las operatividades sociales, las actividades económico productivas y la actividad turística como encadenamiento sinérgico, (MOP 2004a, b). De este modo, con una mirada muy centralista, la debilidad de esta variable es la que define a la Patagonia chilena en un grado de aislamiento alto y de no integración con muchas de las expresiones nacionales como la prevalencia del "ser gaucho", cuestión que ratifica la idea de una relativa autonomía cultural regional y local, en términos de cotidianeidad y personalidad, memoria colectiva e identidad. La distancia entre origen y destino para resolver una necesidad local, entre estar, morar, salir y desplazarse, se vuelve una experiencia recurrente de dificultad y una imagen permanente de sí, vivida como continuum de tiempo tanto desde la vivienda como del territorio. 
Sin embargo, es esa distancia con el centro político y administrativo del país lo que le ha permitido generar autonomías relativas e itinerarios propios en variados aspectos, principalmente en el intercambio económico y cultural transfronterizo, aunque "dependiente alimentariamente" 2 .

Frente a esta condición de difícil desplazamiento, sumado a baja inversión y desprotección respecto de servicios básicos eficientes y de calidad, los habitantes de las diferentes comunas que componen la provincia de Palena, en Chaitén (costa), se constituyen a partir de sus experiencias históricas y en sus referencias espaciales, hablan de "ir a Puerto" (Montt) o "ir a Chile", y los de Futaleufú y Palena (cordillera), definitivamente hablan de "ir a Chile" cuando deben hacer un trámite - requieren de cuestiones especializadas como servicios de salud. En estas dos últimas comunas, el desplazamiento por el interior de Chile significa doce y más horas de viaje, con transbordos en barcazas, inciertos por las condiciones climáticas. "Ir a Chile", en 1956, en Futaleufú, "el pueblo ausente" (Guzmán 2007:161-164), tenía sólo clausuras y como "puerta abierta al mundo Argentina"; hoy, sin grandes alteraciones, muchas veces significa "ir por Argentina" ya que es todo el viaje por tierra y más expedito que por el territorio nacional, además que gran parte de los sistemas de referencia para satisfacer las demandas básicas se ubican al otro lado de la cordillera. Los servicios más importantes como los de salud y los alimentarios son escasamente provistos o servidos por el Estado nacional y particulares. No es diferente la situación en Coyhaique, que a pesar de ser la única "gran ciudad chilena" (capital regional) entre Puerto Montt y Punta Arenas, donde también sus habitantes hablan de "ir a Chile". La situación es más aguda en esta zona, ya que se establece una diferencia muy radical entre los beneficios recibidos por

2 Idea recurrente en las entrevistas a funcionarios del gobierno regional en Coyhaique $y$ los municipios de Chaitén, Futaleufú y Palena.

3 Correspondientes a los años 2012, 2013 y 2014.

4 Son coincidentes las apreciaciones de los jefes de servicios municipales de zonas fronterizas, en cuanto a que beneficiarios de distintos bonos y servicios otorgados por el Estado a través de los municipios, también lo son particulares, funcionarios públicos y militares.

De acuerdo a los registros de campo ${ }^{3}$, esta situación releva algunas cuestiones críticas y estructurantes del vivir patagónico en relación al agenciamiento del Estado: 1) la insuficiente disponibilidad de los servicios dirigidos a la población, 2) los pobres encadenamientos económicos productivos regionales, 3) los problemas de soberanía (MOP 2004a, b) y 4) la indiferenciación respecto de "lo argentino" 4 . Los puntos 1 y 2 demuestran la ausencia de una política territorial y de fomento de la vida rural y tienen como efecto la precaria condición demográfica desde Puerto Montt a Tierra del Fuego. Mateo Martinic (2006) al referirse a la región de Magallanes y su fisonomía territorial, señala que ésta posee tres atributos clave que estructuran la forma de ocupación: 1) el infrapoblamiento rural, 2) una condición irreversible de despoblamiento en las zonas no urbanas y 3) una macrocefalia de Punta Arenas, como centro de concentración demográfica. Los mismos se pueden extrapolar a la región de Aysén y las localidades con "aislamiento crítico", definidas por los niveles mínimos de acceso a servicios básicos y emergencia desde localidades aisladas, en función de umbrales de tiempo (MOP, 2004b), debido a la posición que ocupa Coyhaique en la configuración demográfica y territorial de la región; y más al norte, Puerto Montt, en la región de Los Lagos.

Esta condición social, cultural y territorial de ser y hacer o modus vivendi local es lo que ha instalado desde un lugar no político ni académico, sino militar, la idea de una "frontera interior" en el sur de Chile para la Patagonia. Identifica una condición de aislamiento crítico desde el punto de vista de las horas de desplazamiento, de los servicios, de actividades fijadoras de población y de los encadenamientos productivos, dado por la inconmensurable distancia de los centros políticos y administrativos, la falta de vías estructurantes y de conectividad terrestre y aérea continua ${ }^{5}$. Más allá

en el lado argentino. Especialmente esto acontece en las localidades de Palena y Futaleufú, ya que algunas de las familias tienen bienes a ambos lados de la cordillera, por lo que su residencia es binacional.

5 En términos anualizados, los aeródromos de la provincia de Palena son de baja operatividad, ya que funcionan menos de la mitad de los días. 


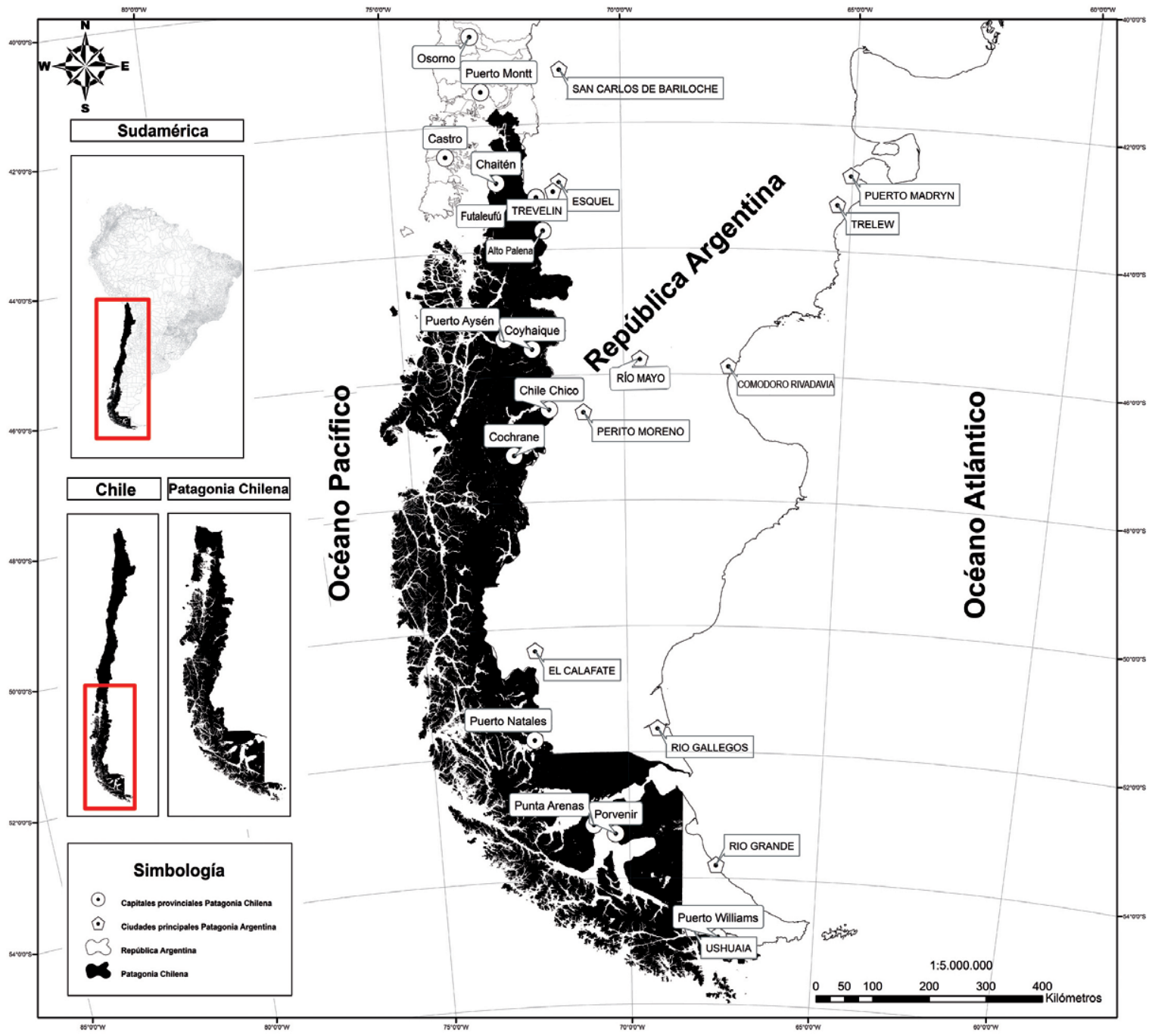

Fig. 1 Mapa de la Patagonia chileno-argenitna, con las capitales provinciales de Chile y ciudades principales de argentina.

de los déficits de servicios que experimentan los poblados y la ausencia de políticas de colonización, se impone una discusión en dos frentes, como señala el ex Comandante en Jefe del Ejército Juan Emilio Cheyre $^{6}$, primero, respecto a la imprescindible y necesaria descentralización y regionalización del país para corregir estas dificultades $y$, segundo, que los territorios bajo soberanía son cultural y demográficamente muy vulnerables, producto del desequilibrio e invertebración evidente frente a otras regiones. Esto último, por cierto debe entenderse dentro de la lógica militar y al mandato constitucional respecto de las fuerzas armadas de defender la patria (las fronteras) y su esencialidad para la seguridad nacional.

Para entender en su magnitud lo señalado, es necesario observar lo que ocurre al otro lado de la cordillera. En la Patagonia argentina se impuso desde los años 50 un modelo desarrollista (industria e infraestructura) y en las provincias australes Neuquén, Río Negro y Santa Cruz se crearon las bases institucionales de un capitalismo tópico y una territorialización -hasta los noventade "manera ejemplar". Hubo, además, un esfuerzo

6 Entrevista en la Radio de la Universidad de Chile, 14 de marzo de 2012. 
por la homogenización de oportunidades y por un mejoramiento escalar de las condiciones laborales $y$ de vida. Fueron importantes la seguridad en el trabajo, el pleno empleo y su formalidad, los sistemas de protección y regulación laboral, la dotación de servicios y la inversión en vivienda. Fueron polos de atracción para población chilena el complejo industrial electrónico de UshuaiaRío Grande, el textil de Trelew y el frigorífico, químico y metalúrgico de Puerto Madryn. En la zona chilena, la excepcionalidad industrial está en Magallanes, donde las empresas ganaderas dejaron un profundo sello de identidad y huellas de lo que fue un modelo de desarrollo en el ámbito local, el frigorífico Bories en Puerto Natales y la Empresa Nacional del Petróleo (Salvia 1999: 9-15).

Entonces, bajo esta idea de frontera interior y de invertebración donde parece terminar la soberanía, que desacredita toda idea de comunidad nacional homogénea, como sistema de oportunidades y de identificación, buscamos entender la Patagonia como un lugar narrativa y permanentemente construido, que la etnografía permite describir y diferenciar entre sujetos, sus representaciones e imaginarios.

\section{LAS NARRATIVAS DEL AISLAMIENTO Y LA CONECTIVIDAD}

De acuerdo a la revisión de información secundaria se observan tres narrativas sobre la Patagonia. La primera, iniciada desde los primeros descubridores y colonos y continuada hasta el día de hoy, se desarrolla desde la perspectiva del explorar y descubrir, identificándola desde un nombre que define el espacio, que es contemporánea de la idea de un sur "excéntrico", construida a partir de un conjunto de calificaciones de contigüidad semántica relacionadas con el fin del mundo, la vastedad, la desolación, el vacío y la presencia de habitantes extraños (Casini 2007:13). La segunda, desde la perspectiva del residir, se sustenta en la idea de distancia, de lejanía, de aislamiento, de falta de vías de conectividad $y$ cierta autonomía, lo que constituye un problema estructural sobre el territorio (MOP 2004: a, b). La tercera, la militar, refuerza la anterior y la observa estratégicamente por la falta de agenciamiento de una institucionalidad estatal con despliegue territorial (MOP 2004: a, b; Cheyre 2012).

Sin embargo, a partir de recientes registros etnográficos emerge una cuarta narrativa que opera como contrapunto a las anteriores y se apoya en la historicidad local, ya que son las mismas condiciones descritas las que se vuelven positivas, es decir, la Patagonia en términos geográficos alcanza y capitaliza un fuerte valor simbólico y material, por el hecho de ser la región más austral del planeta, una de las menos poblada e intervenida por su difícil accesibilidad $y$, por sobre todo, porque es el último confín del mundo donde aún quedan tierras disponibles. Esta narrativa conlleva una doble figura: existe un aislamiento que expulsa y atrae simultáneamente. En el trabajo de campo se observa, por un lado, una identidad cultural que juega entre lo auto atribuido, "de ser aparte del Estado" (de Chile), de "sentirse separados", "abandonados", "distantes del acontecer nacional", "distintos de los chilenos del norte" y de "ser patagónicos" (auto identidad); por otro lado, lo atribuido externamente (alter identidad), que más allá de los modos de vida locales y los estereotipos folcklorizados, resaltan los atributos de su paisaje, sus ecosistemas y la idea de un lugar poco invadido por las fauces de la modernidad, lo que favorece la posibilidad de inventar un proyecto de vida. De esta forma, en la Patagonia se afianza un discurso exógeno -con aportes de nuevos capitales sociales, económicos y culturales- fincado en el paisaje, la escasa densidad poblacional y las dificultades de accesibilidad que ayudan a configurar una expresión social y cultural sui generis. Este discurso "exógeno" se construye en dos concepciones diferenciadas de la naturaleza: la primera, "capitalizada" y la segunda "no capitalizada".

\section{IMAGINARIO DE LA NATURALEZA CAPITALIZADA}

El aislamiento y la majestuosidad casi impoluta del paisaje activan un gran imaginario organizado en torno de la naturaleza y nuevas posibilidades existenciales frente a la "decepción moderna y citadina" 7 . Es frecuente registrar yo lo dejé todo; yo era de Valdivia..., yo era de

\footnotetext{
Agrupamos con estos términos algunos de los relatos testimoniales de personas que han migrado por cambio de estilo de vida
} 
Santiago..., venía de vacaciones hace veinte años, hasta que me quedé aquí, yo paso la mitad del tiempo aquí, y la otra en Estados Unidos, estuve mucho tiempo esperando una oportunidad en el servicio para venirme o yo trabajaba en un hotel en la ciudad y me vine a trabajar como chef al lodge.

Estos registros hablan de una expectativa y valor asociados al retorno a la naturaleza y al cambio de vida como un horizonte de nuevas posibilidades de ser. No obstante, dichas expectativas se tensionan con la amenaza que generan las fuerzas globales, que buscan en la misma vastedad patagónica y en el déficit de agenciamiento del Estado, los recursos genéticos, acuíferos, energéticos y minerales que contiene, convirtiéndose el paisaje en una expresión de "naturaleza capitalizada" o en un sistema específico de "uso y significado" (Escobar 1996, 1997). Esto constituye un dilema de múltiples aristas en relación a los dominios institucionales tradicionales configurados a nivel local, porque como sostiene Saskia Sassen (2012: 473), la desnacionalización, es decir, la apertura del territorio (del despoblado) puede acarrear "un incremento pronunciado de la velocidad, lo que puede a su vez alterar el orden temporal y espacial".

Esto ocurre, por ejemplo, cuando irrumpe la industria del salmón y el proyecto HidroAysén ${ }^{8}$. La industria del salmón corre la frontera social y productiva ubicada inmediatamente al sur de Puerto Montt, llevándola a la comuna de Hualaihué, específicamente a Hornopirén, su capital. La hoy ciudad, que apenas 20 años atrás era un poblado que la habitaban unas quince o veinte familias, que habían explotado maderas desde principios del siglo XX para ser trasladadas a Chiloé, se reconvierte económicamente y es invadida por trabajadores foráneos que realizan

8 El proyecto pertenece al consorcio controlado por Colbún y Endesa-Chile, propiedad de la empresa italiana Enel. Se emplaza en la región de Aysén y busca generar 2.750 MW que pretende trasmitir a través de una línea de alta tensión por más de $2.000 \mathrm{~km}$., atravesando 7 regiones del país, para llevar energía a Santiago y las zonas mineras de Coquimbo y Atacama.

9 La comuna de la Hualaihué es de las pocas comunas que eleva su población, ya que contaba en 1970 con 5.526 habitantes, en 1982 con 6.302 , en 1992 con 7.872 , en una ocupación espontánea de tierras, sin viviendas, servicios de alcantarillado, agua potable y electricidad. Llegaron cientos de trabajadores a la industria acuícola, los cuales configuraron la ciudad, algunos de ellos incluso huían de la ley, por pensiones alimentarias y deudas bancarias, con identidades itinerantes y sin arraigos. Sin embargo, Hornopirén enfrenta dos pasivos: por una parte, la infección ISA (virus de anemia infecciosa del salmón) detectada en 2007 que significó el cierre de plantas y el abandono de instalaciones, dejando a la población sin trabajo pero estabilizada ${ }^{9}$, por lo que la ciudad carga con un bolsón de pobreza y marginalidad que demanda permanentes subsidios; por otra, aparecen los problemas ambientales, ya que la huida de ejemplares de salmones de las jaulas los convierte en depredadores de las especies originarias como las truchas -que eran buscadas por pescadores deportivos internacionales- y otras especies codiciadas por las pesquerías artesanales; siendo también las aguas contaminadas por antibióticos, químicos, desechos orgánicos, hasta transformar sus fondos marinos en desiertos.

Por su parte, HidroAysén, la potencial fuente de acumulación de agua para la generación de hidroelectricidad y su línea de trasmisión, provocan en la población local incertidumbre por el aumento de actividad, circulación de personas, vehículos, el cambio de valor de los terrenos y el alza de los costes de la vida local, ya que, como señala Sassen (2012), es la economía global la que se instala como empresa y mercado global. La obra corresponde al proyecto más emblemático de transformación territorial en Chile e implica la construcción de cinco represas para producir electricidad: dos se emplazarían en el río Baker, el más caudaloso y tres, en el río Pascua. Esta iniciativa, de gran magnitud e impacto social y ambiental cimbra

2002 con 8.210 y en 2012 con 8.702. La población concentrada mayoritariamente en Hornopirén, es la que principalmente sufre el efecto de la crisis del salmón, donde se estima que las pérdidas para la industria superaron el par de miles de millones de dólares y el impacto en el empleo afectó a sobre 20.000 trabajadores, de un número total de más de 50.000 que se empleaban directa e indirectamente en el cluster. Asimismo, sin truchas en los esteros y ríos, dejaron de contratar servicios los pescadores deportivos provenientes de Europa y Estados Unidos. 
todos los rincones de la Patagonia y también del país. Es coherente con los emprendimientos privados neoextractivistas (Svampa 2013) que se han transformado en un verdadero culto ingenieril como lo fueron las represas de Pangue y Ralco en su momento, imponiéndose como norma lo colosal ${ }^{10}$.

Si ubicamos el proyecto en la lógica de la frontera interior, ésta resultaba también ser cobijo frente a la agresividad urbana ofreciendo, dentro del escaso agenciamiento del Estado, una seguridad ontológica a sus habitantes. Pero, una intervención de tal magnitud altera la convivencia interna antes de su construcción e indica que la Patagonia ya no le pertenece solo a sus habitantes; señala que está siendo pensada desde el centro político-administrativo o desde "el Norte", por nuevos intereses globales, nacionales y estatales, lo que narrativamente determina también las nuevas formas de valorización de la naturaleza. El cómo volverla productiva, dentro de un régimen monolingüe de desarrollo, constituye la fórmula de integración territorial, de anulación de las distancias y de fijación de la población, aunque con nuevos y desconocidos habitantes. Más allá de lo energético, la obra ampliaría los límites de una frontera lábil e invertebrada en el ámbito social, cultural, geográfico y ecosistémico, donde los intereses locales comienzan a ser contaminados $y$ subordinados a nuevos discursos no estatales que visionan qué hacer y cómo vivir ahí, ubicándose más allá de las ciudades, poblados y formas up down de constituirse.

\section{LA NATURALEZA NO CAPITALIZADA}

En paralelo, existe otro concepto de naturaleza no capitalizada que se ubica en las antípodas, constituye otro imaginario y pone límites a su uso. Apoyado por principios filosóficos como el "biocentrismo" del noruego Arne Naess (1990), se plantea para el mismo territorio la igualdad biocéntrica, como eje de la llamada "ecología profunda". Esto significa que las cosas que se

10 Raúl Sohr señala que "el tamaño es una protección contra las compras hostiles y un freno para competidores potenciales" (2012:77). Es decir, la racionalidad económica se impone por sobre otras consideraciones estratégicas. hacen no deben privilegiar al ser humano, sino que se deben hacer por todos los seres vivos. Por ello, se destrona la pirámide antropocéntrica y la figura adquiere la forma de una tela de araña, donde los hombres y mujeres ocupan solo un lugar en ella. Esta formulación es esencialmente crítica respecto de la concepción de desarrollo de Occidente, ya que los problemas ambientales son considerados producto de una manifestación física de las formas de operar de nuestra sociedad y cultura.

Este conceptoloencarna el caso de Pumalín ${ }^{11}$, el primer parque privado conservacionista (300.000 hectáreas) y uno de los predios del ambientalista norteamericano Douglas Tompkins, propietario en Chile y Argentina de grandes extensiones de tierra y principal donante de algunas de ellas a estos países. Su concepto preservacionista de la "ecología profunda" le permite la posibilidad de desarrollar una autonomía administrativa sobre el territorio, es decir, tener reglamentaciones propias en sus 900.000 hectáreas de tierras adquiridas (Sánchez 2009: 71). Pumalín es un concepto y un lugar donde se aprecian los últimos alerces de 3.000 años, en el que está prohibido cazar, pescar, encender fuego, derribar un árbol o arrancar una especie vegetal; los ríos, las aves, los peces y los animales circulan libremente, asegurando su futuro ${ }^{12}$.

De este modo, la naturaleza o el espacio pueden ser concebidos sin límites, pero los territorios habitados y apropiados sí los tienen (Barabás 2004: 148). Éstos no solo ofrecen lo que pudiésemos llamar recursos escasos, sino también construcciones subjetivas, afectos, seguridades, filosofías, imaginarios y cargas simbólicas que ponen límites a las actividades, porque se reconocen en ellos lugares significativos. Así, el espacio no debe considerarse únicamente como un objeto pasivo o simple soporte físico, sino como un agente activo y dinámico con influencia en las relaciones socioeconómicas (Caravaca 1998: 41). La valorización de los rápidos del río Futaleufú, los alerces milenarios de Pumalín y los reflejos del lago Espejo en la provincia de Palena, así como el río

11 En mapudungun significa puma verde.

12 En abril de 2014 Douglas Tompkins ofrece donar el Parque Pumalín al Estado chileno dentro del año en curso, con la condición de que siga siendo un parque conservacionista (La Tercera 20/04/2014). 
Pascua y el Baker en la región de Aysén, muestran apropiaciones subjetivas que hablan de una territorialización, porque contienen para muchos un sentido de la existencia que puede prescindir de mega emprendimientos, ya que ellos sólo pueden ser apreciados en su valor económico, a más de 3.000 kilómetros de distancia, en el Desierto de Atacama.

Sin embargo, frente a la amenaza socioterritorial y socioambiental de la Patagonia por una posible desposesión de los valores asociados y el secuestro de la experiencia local histórica o reciente, encontramos un reclamo geopolítico local $e$ internacional que la supera en sus límites físicos, porque la oposición en red a fórmulas mineras, hídricas y energéticas de vertebración territorial, constituyen un enriquecimiento simbólico del territorio y una apropiación representacional, lo que se establece como un nuevo activo. Se instala un cierto derecho colectivo nacional e internacional respecto de su defensa y también de memoria de larga duración local entre los descendientes de los pioneros y primeros colonos.

Se activa una "conciencia universal" en cuanto a que la Patagonia debe ser preservada, porque la biodiversidad de la terra australis está bajo amenaza y resultaría difícil encontrar en el mundo un lugar como éste para iniciar un proyecto de vida lejos de la ciudad y sus problemas. En este sentido, cuando externamente se destacan sus atributos, aumenta su valor y se le aprecia como una reserva natural del planeta y de opción de vida en términos existenciales, se promueve un tipo de migración por "amenidad" (González 2011: 1102), idea que indica la renuncia a un modo de vida y el interés por instalarse en otro lugar, que ofrezca una calidad superior en lo ambiental y cultural al lugar de residencia. Estas características, cuando son reconocidas, asumidas y puestas en un discurso, sitúan al territorio patagónico como una marca, es decir, se le potencia como un signo distintivo de un estilo de vida.

\section{LA PATAGONIA COMO UNA MARCA TERRITORIAL}

...el sol está a muchos más años luz de aqui que de cualquier otra región del planeta

(Patricio Manns 1997).
En un viaje de aventuras por el cono sur, lejos de la guerra de Vietnam, al pie del monte Fitz Roy (o Chaltén), un grupo de jóvenes norteamericanos decidió que no podía regresar sin escalar aquello que tenía el aspecto de un helado gigante de crema americana (Sánchez 2009:75). La fascinación por el ascenso de los 3.405 metros de "la montaña que humea" y por el paisaje, hizo que Roy Gerar, uno de los aventureros junto a Douglas Tompkins, al retorno fundara la compañía textil Patagonia, cuya franquicia de prendas out doors hoy se encuentra en todo el mundo. Como se evidencia en la página web de la empresa (http://www.patagonia.com/ us/home), se promociona un resguardo ético con la naturaleza, buenas prácticas, una amistad entre los hombres y mujeres con ésta y con una buena dosis de aventura y actitud de descubrimiento.

Patagonia, entendida en esta investigación como una figura narrativa anclada en el espacio y el territorio, asociada a la lejanía, la vida difícil, desafiante, riesgosa, intimista y desolada, en los últimos años se renueva simbólicamente como un concepto verde, lugar de refugio, turístico y con un magnetismo casi ilimitado, ya que es uno de los lugares internacionalmente recomendados que "hay que conocer" o "quedarse". Viajar a Chile a recorrer su larga figura, es para dirigirse principalmente a tres lugares: San Pedro de Atacama, Isla de Pascua y la Patagonia. En este sentido, decir Patagonia es tan grandioso como decir Ártico, Desierto de Atacama, Himalayas, Sahara, Kalahari, Galápagos o Amazonía. Todos estos lugares despiertan un imaginario que evoca y transporta a un paisaje, a la grandeza de la naturaleza y a unas condiciones ambientales particulares que capitalizan una reputación única.

Se le aprecia como un destino turístico de nivel mundial, con atractivos como las Torres del Paine, laguna San Rafael, capillas de Mármol y glaciares como Perito Moreno. Además, es identificada por sus lagos y ríos, para la práctica de kayak, rafting, flyfish, trekking y las expediciones en bicicleta. Se destacan sus bosques cerrados, lagunas de aguas claras, de azul zafiro y verde jade, orillas teñidas de rosa por los flamencos; sus cientos de canales que caen de picos blancos montados unos sobre otros; tonos naranjas que se descuelgan por los cerros blancos y enceguecedores. También se reconocen 
sus ríos crecidos, cursos de agua que se deslizan con fuerza por resbaladizas piedras, nubes cargadas, árboles muertos y vestigios de bosques eliminados por el fuego; infaltables guanacos, zorros, liebres, ñandúes, cóndores y miles de ovejas.

Entendida como una marca, como la expresión "material" del imaginario sobre la naturaleza como producto, la voz Patagonia define una condición que activa un imaginario formado por un sistema de imágenes, signos y símbolos relativos al paisaje y la libertad. Una narrativa con atributos ambientales positivos y características propias que llevan al espacio abierto, a la estepa, al viento, a las montañas, los ríos y los océanos, a lo inhóspito y a lo desafiante. Pero al mismo tiempo, revela una orientación económica dirigida a un tipo de consumidor "verde"; un presumidor (profesional consumer) que es movido por sus valores $y$ con potentes capitales culturales $y$ simbólicos en términos de Bourdieu (1998).

La Patagonia se perfila como un posible edén, un lugar de salvación, un refugio de última esperanza y con ello va quedando atrás la madre tierra indígena de los desaparecidos selk'nam y yámanas y de las oportunidades de los inmigrantes que llegaron a través del estrecho de Magallanes. Quedan los ecos de los posicionamientos en los espacios en los que actuaron los sujetos como cazadores y recolectores o como perseguidores de nativos, misioneros, buscadores de oro y estancieros con la riqueza que prodiga la naturaleza hostil; los vestigios de las estructuras temporales en las que éstos se movieron, que dieron forma a sus identidades psicológicas, sus motivaciones, voluntades, búsquedas y proyectos. Este sustrato en el que convergen nativos e inmigrantes, paisaje vasto, aislamiento, soledad, sombra, vida y muerte, constituye también el campo semántico del vocablo Patagonia (Arratia 2011: 73), circulando promocionalmente hoy por muchos rincones del mundo.

También es un desierto. No de arena y piedras. Tiene matorrales y arbustos espinosos, de hojas y filos grisáceos, los que exhalan un olor amargo cuando los aplastan. Este desierto, desolado y duro, con su inmensa vacuidad ofrece cierta serenidad a los hombres y mujeres; embruja,

13 En Futaleufú, algunos recién llegados creen que para ser un auténtico futaleufuense se debe "tomar mate, bailar sobrecoge, atrapa, seduce y no libera. Si caminas mucho, es probable que no necesites ningún otro Dios, dice Bruce Chatwin (2004: 45); el poncho, el mate y el cuchillo son para muchos las pertenencias más fundamentales y para otros también pueden serlo $^{13}$. Mirada en la profundidad del tiempo, ello no exime de cierta heroicidad la vida cotidiana de pioneros y colonos, especialmente cuando sabemos que la decisión de ocupar y colonizar el extremo sur por parte del Estado de Chile, data recién de 1843 con la fundación del Fuerte Bulnes en el estrecho de Magallanes; y que fue y sigue siendo la naturaleza desafiante, riesgosa y confrontacional, lo que dificulta hasta el día de hoy la colonización extensiva en toda la Patagonia, incluso en su zona norte, como la provincia de Palena. Los pioneros, más que conocimientos tuvieron ojos para aprender, se nos señala. ${ }^{14}$

Los colores, olores y sonidos que se ofrecen a los sentidos sustentan una "marca verde". El paisaje y el territorio filmado, fotografiado y divulgado permanentemente, se presenta como portada en las revistas de viajes y de los periódicos del mundo que promocionan lugares con particularidades ecosistémicas; sus atributos son percibidos, apropiados, interpretados, narrados, imaginados, deseados y representados positivamente desde muchos lugares. Así, la Patagonia opera como un gran discurso verde sobre uno de los últimos lugares donde queda espacio (como lugar no intervenido) y como una marca cuyo posicionamiento apunta a la activación de una vivencia, a las emociones, los sentidos y la contención de actividades invasivas. Como imaginario de una frontera de lo único e irrepetible, del deseo que despierta por recorrerla en su vastedad y abandono, provoca una comunicación efectiva con el paisaje, "de buen gusto y de buen vivir". Transmite evocaciones y asociaciones míticas y místicas, ya que se sacraliza la naturaleza llevándola a lo más íntimo del yo.

\section{LA EXPERIENCIA DE VIVIR LA MARCA PATAGONIA}

No es de extrañar que desde su lado sur y desde las entradas del norte chileno y argentino se desarrollen inversiones de enclave y que antiguas

chamamé y bajar el río en balsa o kayak".

14 Registro de campo en Puerto Natales, enero de 2013. 
estancias ovejeras hayan sido reacondicionadas con una rusticidad sofisticada y pensadas especialmente para un público extranjero de altos ingresos, que busca "desaparecer del mundo", "pasar inadvertido"; o que sea ofrecida para la práctica de deportes extremos o de elite en escenarios privilegiados, escasamente vinculadas con la población y economía local. De este modo, semánticamente la Patagonia se renueva como el confín del mundo, la finis terrae, la frontera de la civilización, la imagen de parte del globo que se nos guarda en reserva, un fragmento de belleza inmaculada, de particularidad estética invaluable. Se reafirma como un espacio de excepción que genera una polaridad valorativa: es la antítesis de la vida ordinaria, del frenesí urbano consumista, del agobio de las tareas y la escasez de tiempo; un topoanálisis nos muestra que la dificultad producida por el "aislamiento histórico", que cruza la existencia cotidiana de los residentes, es precisamente lo deseado por los visitantes y los nuevos colonos.

La experiencia de aislamiento geográfico en el ritmo de sus habitantes revela elementos "geohistóricos" (Braudel 1976) que anuncian una amalgama indisoluble entre la experiencia del espacio y el tiempo, pues los sistemas de producción y reproducción de las comunidades tienen un soporte espacial singular: lejanía, difícil acceso y dificultades de desplazamiento, como pormenoriza el estudio del Ministerio de Obras Públicas (2004a, b). Así, para los pobladores históricos, es el lugar donde las opciones humanas están determinadas, en gran medida, por la geografía y su paisaje, porque la vida y el tiempo de los lagos, los bosques, los peces, las aves y los animales se igualan al humano.

La Patagonia opera como una marca que tiene un aura singular: crea una expectativa en torno a un proyecto de vida y despierta una sensibilidad mayor sobre la naturaleza y su majestuosidad. Para sus defensores en red, ambientalistas, turistas y consumidores verdes, como lo fue en el pasado para inmigrantes, anuncia un lugar donde comienza la aventura y la posibilidad de acceder a rincones y parajes únicos, y la posibilidad del refresco de la propia existencia. Pensada desde la "economía de la experiencia" provee vivencias,

15 Registro de campo en Futaleufú, octubre de 2012.

16 Registro de campo en Futaleufú, octubre de 2012. de entretenimiento como las cabalgatas, el "enduro ecuestre", el ser "baqueanos por un día"; escapistas, como el anonimato, huida de la vida urbana; educativas, aprendizajes de la diversidad natural y cultural; y contemplativas, de apreciación del paisaje; así como la posibilidad de estar ahí, sentir, hacer y aprender (Pine y Gilmor 1999). Para quienes recorren su territorio se trata de descubrir, despertar sensaciones y emociones detonadas por el paisaje, por la inmersión en la vida local y por la ausencia de tentaciones modernas. Además de vivir una experiencia superlativa de estar donde aún no ha llegado nadie ${ }^{15}$, se convierte en un repertorio de opciones que favorece la transformación de sí mismo, en el límite de la conversión hacia una nueva vida.

Aunque los poblados de la Patagonia siguen siendo el lugar donde nadie ha regalado nada ${ }^{16}$, constituyen también los refugios donde se puede tener una segunda oportunidad ${ }^{17}$. Hoy, como ayer, las antiguas poblaciones locales se subordinan a la naturaleza, porque la naturaleza aqui gira demasiado rápido, es imprevista, despierta un volcán, viene un aluvión, un terremoto blanco, una caída de árboles que corta el camino, la lluvia intensa que impide que llegue un avión o el helicóptero, la barcaza se tiene que fondear por 30 y más horas esperando que amaine el temporal $^{18}$. Es la grandeza y fuerza del viento, el agua y el bosque lo que hace que la vida propia y ajena se lea en otro código y que sea precisamente el dramatismo local, lo que se redescubre como contraparte de la modernidad urbana y dote de forma y contenido a la marca, al resignificar la adversidad como una característica a ser desafiada en la aventura, en la permanencia y en el territorio patagónico.

Lo especial de su paisaje y de sus condiciones no es nuevo, sino que representa un continuo en el tiempo. Mítico ha resultado desde los años sesenta el llamado "paralelo 42" donde se ubica El Bolsón (Argentina), en el lado oriental de la cordillera, lugar elegido para el asentamiento de una comunidad que lo prefirió como huida de la Guerra Fría, donde los efectos de la radiación derivados de la amenaza nuclear no llegarían. Ahí, cargados de energías y de buenas ondas

17 Registro de campo en Futaleufú, octubre de 2012.

18 Registro de campo en Chaitén, octubre de 2012. 
(Sánchez 2009: 30) se instaló una colonia hippie o contracultural en clave sociológica de ese tiempo; los recién llegados, rockeros y alternativos, fueron migrantes motivados por un cambio de estilo de vida, lifestyle migrants, que buscaban salvación y enfrentar los anunciados problemas ecológicos y del mundo bipolar.

Bruce Chatwin (2004: 10) en su libro En la Patagonia, lo señala así: Excluimos las islas del Pacífico porque las islas son trampas. Descartamos Australia y Nueva Zelanda y seleccionamos la Patagonia como la región más segura del planeta. [...] Imaginé una cabaña con troncos baja, con techo de tejas, calafateada contra las tempestades, con un crepitante fuego de leña en el interior y las paredes cubiertas con los mejores libros: un lugar donde vivir cuando el resto del mundo volara en pedazos.

El historiador argentino Ernesto Bohoslavsky (2009: 49-50), en su libro El complot patagónico señala: La Patagonia es como la finis terrae de la experiencia humana [...] es fácil extraviarse físicamente, pero también es donde resulta más sencillo encontrarse con el yo salvaje, porque alli la vida es auténtica, plena o natural.

En la terra australis, como lo fue el "lejano Oeste", se puede ser no solo colono, sino pionero. Las miles de hectáreas compradas por multimillonarios extranjeros dueños de imperios de la ropa, la televisión, los alimentos, equipos de fútbol y jet set internacional, tales como los hermanos Benetton, Ward Lay, Ted Turner, Joseph Lewis, Christopher Lambert, Bruce Willis, Leonardo DiCaprio, Silvester Stallone, entre otros, les pueden permitir ser "el primer hombre" al poner un pie en lo virgen; son émulos de Orélie Antoine de Tounens, "rey de la Patagonia y la Araucanía", porque hay excentricidades o gustos que parecieran no tener límites en el actual mercado de la "experiencia".

No desconocemos que algunos de estos "nuevos vecinos" y otros más anónimos en la Patagonia, puedan tener sueños muy privados, los que también podrían ser muy sospechosos. El objetivo del control del territorio puede estar en fines especulativos, en la creación de una colonia, en la captura de una trucha de grandes proporciones o puede ser el material genético de la biota o del agua. Encontramos también inversiones como reconversiones de estancias en hoteles boutiques, Premium o VIP. Destacan la invención de un nuevo tipo de asentamientos como El Chaltén ${ }^{19}$, en Argentina $y$, del lado chileno, lodges que operan de manera desterritorializada, ocupados por personas de Estados Unidos y Europa que comparten las mismas necesidades y que no tienen ninguna vinculación con el territorio horizontal en el que viven los lugareños. Estas personas pagan por la exclusividad y por el anonimato, participando de una matriz que técnicamente más arriba hemos llamado economía de la experiencia. Y así lo indica la oferta: "un lugar donde recibirá y disfrutará los extractos de nuestra tierra, sales y hierbas que lo harán experimentar el encanto de nuestra Patagonia".

La Patagonia, por sobre todo, ofrece el estar de otra manera en relación al tiempo y al espacio. Es una marca que está por sobre lo físico. Lo local se pone en un discurso global, inclusive desterritorializado; hay un conocimiento espacial y estratégico que se ha diseminado reticularmente, donde los agentes que actúan son más que los pobladores locales, ya que ambientalistas y "anticapitalistas" de todo el mundo promueven su defensa y conservación.

\section{CONCLUSIONES Y COMENTARIOS FINALES}

En este artículo hemos propuesto la idea de una Patagonia producto, asociada a una "oferta verde" y una "demanda verde" que constituiría la figura de una marca territorial, la que se encuentra en tensión con otros imaginarios y otras formas de naturaleza capitalizada. Esta noción refuerza la idea de que la Patagonia excede su territorio. Por una parte se encuentran las posibilidades concretas de la población local para hacer la vida; $y$, por otra, aparecen las representaciones de agentes exógenos. De ahí, realzando cierta autonomía local, es decir, la propia historicidad expresada en cotidianeidad, que las narrativas experimentan in situ encuentros y desencuentros materiales y simbólicos y que ésta construcción plurinarrativa 
deba ser abordada como un problema de economía política.

Como ha indicado Karl Polanyi (1992), al ser la producción una relación entre hombre y naturaleza, la entrada al mercado del territorio y del paisaje supone la mercantilización de ambos, quedando sujetos a las reglas de la oferta y la demanda. Esta condición axiomática, leída como confluencia de intereses distintos o de valores de uso y de cambio, alteraría los rasgos más básicos de las comunidades como son el parentesco, la vecindad y las actividades tradicionales. La condición de ingreso del mercado transnacional a las comunidades, que viven en el Chile invertebrado de la frontera interior, a través de un régimen extractivo de naturaleza capitalizada, como sabemos, es lo que siempre desarticula los equilibrios prevalecientes y las reglas locales.

La "marca" parece estar ganando posición y se impone por sí misma en términos de marketing, demostrando que Patagonia no es solo el escenario del soporte donde algo acontece. El componente geográfico y espacial ha quedado incluido en un marketing global, porque ha conciliado aspectos abstractos (un intangible) y aspectos figurativos (la imagen del paisaje). De la Patagonia se escucha $y$ se conoce, son miles y millones de hombres $y$ mujeres que desde muchos rincones rechazan las externalidades simbólicas y materiales que se generarian en el territorio producto de una capitalización de tipo extractivista. La invaluable experiencia del habitar la naturaleza en el confín del mundo, el imaginario sobre la vida y la belleza, la posibilidad de encontrarse a sí mismo y la economía de la experiencia como forma de hacer turismo verde, se vuelven imposibles con las anunciadas intervenciones a gran escala.

La complejidad observada en el territorio invertebrado es sobre los imaginarios que visionan su destino; lo es sobre la noción de desarrollo, de economía, de marketing y lo es también en términos ambientales, filosóficos, antropológicos, sociológicos y comunicacionales. Por una parte, desde la perspectiva centralista, el territorio aparece fácticamente como desprovisto del habitar por la escasa densidad de población, siendo desvalorizado de su carga simbólica y transformada sólo en un valor de cambio. Por otra parte, desde sus habitantes, aparece el valor de uso del espacio, el del habitar cotidiano y sus cargas semánticas, de la convivencia con los elementos, el mundo transfronterizo y muchas veces autónomo; el de la relación de sentido que las comunidades codifican como valor cultural, la crítica a la economía extractivista y las filosofías que lo recorren. Al final, el conflicto se expresa entre los límites del crecimiento, del desarrollo local, y el crecimiento sin límites del modelo de naturaleza capitalizada.

La Patagonia tiene sentido no sólo para sus habitantes dispersos, los que probablemente nunca se conocerán entre sí, lo tiene también para otros que sin conocerla físicamente la reinventan y defienden en muchas partes del mundo, formando una nueva comunidad imaginada que protege las últimas tierras disponibles. Por ello, constituye un macroespacio narrativo y su éxito o reconocimiento está en lo que significa la lejanía y la exclusiva posibilidad del "vivir de otra manera". No sólo es un pulmón y una reserva de agua dulce y biodiversidad, sino que partes de su activo, para un mundo ávido de experiencia y de reencuentro con la naturaleza, seguirán siendo las vías ripiadas y la débil articulación entre las localidades.

La amenaza de la degradación de su singularidad ambiental y cultural es lo que también fortalece la marca del territorio. Interiormente, lo que está en juego, es el cambio, la transformación territorial y la cohesión social; cómo se forma o da curso a una nueva sociedad con la ruptura "del aislamiento" a cuestas y cómo se hace sostenible y sustentable una comunidad con nuevas tensiones, porque el desarrollo y el encadenamiento productivo lo es en relación al bien-estar de las personas y eso es lo único que tiene sentido.

\section{BIBLIOGRAFÍA}

Anderson, B. (2003).Comunidad imaginada. Buenos Aires: Fondo de Cultura Económica.

Appadurai, A. (2001). La modernidad desbordada. Dimensiones culturales de la globalización. Montevideo: Ediciones Trilce y Fondo de Cultura Económica.

Arratia, M. (2011). Fundación narrativa de la Patagonia. Punta Arenas: Ediciones Universidad de Magallanes.

Bandieri, S. (2011). Historia de la Patagonia. Buenos Aires: Editorial Sudamericana.

Barabás, A. (2004). La construcción de los etnoterritorios en las culturas indígenas de Oaxaca. Desacatos. Revista de Antropología Social 14, 145-168. 
Berger, P. \& Luckmann, T. (1999). La construcción social de la realidad. Buenos Aires: Amorrourtu Editores.

Bohoslavsky, E. (2009). El complot patagónico. Nación, conspiracionismo y violencia en el sur de Argentina y Chile (siglos XIX y XX). Buenos Aires: Prometeo Libros.

Bourdieu, P. (1998). La distinción. Criterio y bases sociales del gusto. Madrid: Taurus.

Braudel, F. (1976). El mediterráneo y el mundo mediterráneo en la época de Felipe II (vol II). Madrid: Fondo de Cultura Económica.

Caravaca, I. (1998). Los nuevos espacios emergentes. Estudios Regionales 50, 39-80,

Casini, S. (2007). Ficciones de la Patagonia. La construcción del sur en la narrativa argentina y chilena. Chubut: Fondo Editorial Provincial, Secretaría de Cultura del Chubut.

Chatwin, B. (2004). En la Patagonia. Barcelona: Quinteto.

Cheyre, J. (2012). Entrevista, Radio Universidad de Chile.

Escobar, A. (1996). Viejas y nuevas formas de capital y los dilemas de la biodiversidad. En Pacífico: ¿desarrollo o diversidad? Estado, Capital y Movimientos Sociales en el Pacífico Colombiano. Bogotá: Cerec-Ecofondo.

Escobar, A. (1997). Biodiversidad, Naturaleza y Cultura: localidad y globalidad en las estrategias de conservación. México: UNAM.

González, R. (2011). Los procesos de migración de amenidad y la competitividad de destinos turísticos de montaña del oeste canadiense y de la norpatagonia Argentina. Estudios y Perspectivas en Turismo 20, 1102-1122.

Guzmán, N. (2007). Estampas populares de Chile. Crónicas. Santiago: RIL Editores.

Latorre, M. (1965). Chile país de rincones. Santiago: Editorial Zig-Zag.

Lindón, A, D. Hiernaux \& M.A. Aguilar. (2006). De la espacialidad, el lugar y los imaginarios urbanos: a modo de introducción. En Lindón, A, M. A. Aguilar \& D. Hiernaux (Eds.), Lugares e imaginarios en la metrópolis. (pp.19-25). Barcelona: Editorial Anthropos y Universidad Metropolitana.

Manns, P. (1997). El corazón a contraluz. Emecé Editores, Buenos Aires.
Marcus, G.E. (1995). Ethnograpy in/of the World System: the Emergence of Multi-Sited Ethnograpy. Annual Anthropogycal Review 24, 95-117.

Martinic, M. (2006). El poblamiento rural en Magallanes durante el siglo XX. Realidad y utopía. Magallania 34 (1), 5-20.

Ministerio de Obras Públicas (MOP). (2004a) Plan de inversiones para la conectividad Austral. Santiago.

Ministerio e Obras Públicas (MOP). (2004b) Estudio de accesibilidad territorial. Fronteras Interiores. Santiago.

Molina, W. (2011). Identidad Regional en Magallanes, sus expresiones simbólicas y territoriales. Magallania 39 (1):59-69.

Naess, A. (1990). Ecology, Community and Lifestile: Outline of an Ecosophy. Cambridge: Cambridge Universe Press.

Pine, J. \& J. Gilmore. (1999). The Experience Economy. Boston: Harvard Business School Press.

Polanyi, K. (1992). La gran transformación. México: Fondo de Cultura Económica.

Rosman, M. (1992). Empowering Place: Multilocality and Multivocality". American Anthropologist 94, 640656.

Salvia, A. (1999). Sectores que ganan, sociedades que pierden. Procesos y balance general. En A. Salvia (Ed.). La Patagonia de los noventa: sectores que ganan, sociedades que pierden. Buenos Aires: Editorial La Colmena.

Sánchez, G. (2009). La Patagonia vendida. Los nuevos dueños de la tierra. Buenos Aires: Marea Editorial.

Sassen, S. (2012). Territorio, autoridad y derechos. De los ensamblajes medievales a los ensamblajes globales. Buenos Aires: Katz.

Sohr, R. (2012). Chile a ciegas. La triste realidad de nuestro modelo energético. Santiago: Ramdom House Mondadori.

Soja, E. (1996). Thirdspace. Journeys to Los Angeles and other real and imagined places. Oxford: Blackwell Publishers.

Svampa, M. (2013). "Consenso de los commodities" y lenguajes de valoración en América Latina. Nueva Sociedad 244, 30-46. 
